\title{
Normal and five-fingered hand: comparative $X$-ray morphometry in the post-natal age
}

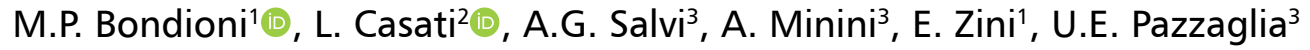 \\ ${ }^{1}$ Department of Radiology, Department of Medical and Surgical Specialties, Radiological Sciences and Public Health, \\ University of Brescia, Italy \\ ${ }^{2}$ Department of Medical Biotechnology and Translational Medicine, University of Milano, Italy \\ ${ }^{3}$ Orthopaedic Clinic, Department of Medical and Surgical Specialties, Radiological Sciences and Public Health, \\ University of Brescia, Italy
}

[Received: 18 June 2020; Accepted: 1 July 2020]

Background: Five-fingered hand (5-FH) with completely developed phalanges is a rare phenotype observed so far only in humans and characterised by three phalanges of the $1^{\text {st }}$ ray. A long-lasting, debated question is if the missing element of the normal hand $1^{\text {st }}$ ray is the metacarpal or the phalanx. In this study, comparative $X$-rays morphometry of long bones in normal and 5-FH is carried out with the aim to face this question through homology analysis of long bone segments in the transverse and longitudinal line of normal hand and 5-FH.

Materials and methods: I $n$ the normal hand $X$-rays $(n=20)$ and in a 5-FH X-rays series $(n=9)$ the relative length of each segment on the ray total length and the index of growth rate (IGR) were assessed. The calculation of the first parameter in normal hand bi-phalangeal thumb was carried out on the $3^{\text {rd }}$ ray total length in the same hand.

Results: The parameters of relative length and the proximal/distal growth rate asymmetry in the post-natal period (assessed through the IGR) confirmed in 5-FH the homology of all the five segment on the transverse line. In the normal control hand, the relative length assessment methodology was biased by the missing segment of the thumb, therefore, the reference to the $3^{\text {rd }}$ ray total length in the same hand (instead of the 15t), allowed the homology analysis of the thumb metacarpal and $1^{\text {st }}$ phalanx with the lateral segments $\left(2^{\text {nd }}-5^{\text {th }}\right.$ ray) of the same hand. The 5-FH analysis was used to choose the more appropriate reference ray for the normal hand group.

Conclusions: The comparative analysis of relative lengths and IGRs in the two groups suggested homology of the (anatomical) $1^{\text {st }}$ metacarpal with the $2^{\text {nd }}-5^{\text {th }}$ proximal phalanges in the same hand and that of the (anatomical) $1^{\text {st }}$ proximal phalanx with the $2^{\text {nd }}-5^{\text {th }}$ mid phalanges. These data suggest that the missing segment of the normal hand thumb is the metacarpal. (Folia Morphol 2021; 80, 2: 403-409)

Key words: five-fingered hand, triphalangeal thumb, hand post-natal ossification pattern, hand segments morphometry homology

Address for correspondence: M.P. Bondioni, MD, Department of Medical and Surgical Specialties, Radiological Sciences and Public Health, University of Brescia, Piazzale Spedali Civili Brescia, 25123 Brescia, Italy, tel: 0039 0303996291, fax: 00390303996034 , e-mail: mariapiabondioni@gmail.com

This article is available in open access under Creative Common Attribution-Non-Commercial-No Derivatives 4.0 International (CC BY-NC-ND 4.0) license, allowing to download articles and share them with others as long as they credit the authors and the publisher, but without permission to change them in any way or use them commercially. 


\section{INTRODUCTION}

In the foetal period and after the formation of the primary ossification centres, it is possible to document that the length increment of the long bone cartilage anlagen in the hand occurs with a symmetric proximal and distal growth of the meta-epiphyses $[12,13]$. This process is controlled by the chondrocyte proliferation rate and orientation in the transition zones between the primary ossification centre of the diaphysis and the epiphyses [12]. In a more advanced developmental stage (late foetal and post-natal period), a distinct ossification centre is formed transforming the interposed cartilage layer between the ossified diaphysis and the epiphyseal ossification centre into the metaphyseal growth plate cartilage. This provides the longitudinal growth until the skeletal maturity is reached. The opposite epiphyseal end undergoes a different type of ossification indicated with the term of "pseudo-epiphysis" [5]. Therefore the pattern of longitudinal growth changes becoming asymmetric, with a higher distal growth rate in the $2^{\text {nd }}-5^{\text {th }}$ metacarpals and an inverted proximal growth in the $1^{\text {st }}$ metacarpal and in all the phalanges.

Five-fingered hand (5-FH) with completely developed phalanges (excluding delta or severely underdeveloped phalanges) is a rare phenotype. To the best of our knowledge, it has been observed only in the human species. X-ray morphometry of this phenotype has been used to compare length, shape and index of growth rate (IGR) of each ray bone element without the bias of the missing segment of the thumb. The result of this study are considered in the context of the long lasting question if the missing $1^{\text {st }}$ ray segment of the normal, human hands a metacarpal or a phalanx $[10,15]$. No morphometric analysis of this type has been so far carried out on 5-FH phenotype because its uncommon occurrence prevented the collection of a sufficient number of X-rays for the analysis. The aim of this paper is to document through published X-ray images of 5-FH reported cases [6, 14, 20-22] the length homology of the hand segments in the transverse line, the length proportions along the ray longitudinal line, and the pattern of growth which determine the overall shape of each segment class. These data were compared with the normal hand population. In this context, the 5-FH phenotype deserves a remarkable interest because it can be related to the evolution of the opposable thumb in hominids and some anthropoid species.

\section{MATERIALS AND METHODS}

The search of published articles on the topic was carried out on PubMed data base using the terms "triphalangeal thumb" or "five-fingered hands". Five papers provided X-ray of image quality, which should allow reliable measurements: in all 9 hands in 8 reported cases were analysed (Table 1). The low number of studied cases was due to the rarity of this mutation (basically a normal hand with three phalanges associated to a variable limitation of the opposition). A further limit was represented by the quality of the printed X-ray images, which required a further selection for a reliable morphometry. The selected X-ray images were digitalized in JPEG format with a scanner (when no PDF was available). Elaboration with Adobe Photoshop was carried out using only the brightness/contrast or the "relief" function of the program. Twenty normal hand X-rays of children between 8 and 15 years old was selected from the Paediatric Radiology archives (ASST Spedali

Table 1. Selected case reports of five-fingered hand and data available from the articles (columns $1^{\text {st }}-3^{\text {rd }}$ ), total number of subjects (column $4^{\text {th }}$ ), total number of scanned hand X-rays where measurements and calculation of relative length and growth rate index assessment were carried out (column $5^{\text {th }}$ )

\begin{tabular}{|c|c|c|c|c|}
\hline Selected case reports & Subject age & Parentage & Number of cases & Number of analysed X-rays \\
\hline \multirow[t]{2}{*}{ Heiss (1957) } & Adult & Mother & 1 & 1 \\
\hline & New-born & Son & 1 & 0 \\
\hline \multirow[t]{2}{*}{ Oazi and Kassner (1988) } & Adult & & 1 & 2 \\
\hline & Child & & 1 & 1 \\
\hline Zuidam et al. (2006) & Adult & & 1 & 1 \\
\hline Zuidam et al. (2010) & Adult & & 1 & 1 \\
\hline \multirow[t]{2}{*}{ Zguricas et al. (1997) } & Adult & & 1 & 2 \\
\hline & Adult & & 1 & 1 \\
\hline Total & & & 8 & 9 \\
\hline
\end{tabular}


Civili di Brescia). The radiographic survey had been carried out for trauma of wrist/finger because of a dubious fracture, which was not confirmed by $X$-rays; otherwise, for assessment of the skeletal age. X-rays were taken in anterior-posterior hand projection at the standard distance of $50 \mathrm{~cm}$ from the radiogenic tube. The research was approved by University of Brescia DSMC Council.

\section{Length analysis}

The length assessment of each hand segment (metacarpals and phalanges) was carried out on digitalised images measuring the distance from the proximal to the distal end along the longitudinal mid axis with the programme "Cell" (Soft Imaging System $\mathrm{GmbH}$, Munster, Germany). The epiphyseal ossification centres were included in the measurement: most of the selected X-rays were of adolescents or young adults, therefore with the full developed series of epiphyseal nuclei. The total ray length was calculated as the sum of the metacarpal and of the same ray phalanges. The relative length of each segment in the same 5-FH was calculated on the total length of its own ray. In the normal hand population, the relative length of the thumb segments was calculated on the $3^{\text {rd }}$ ray total length in the same hand, those of the other fingers on the total length of the corresponding ray.

\section{Longitudinal fingers' growth rate index (IGR)}

In metacarpals' and phalanges' X-rays, the narrower circumpherence of the diaphysis (deduced from the narrower A-P diameter in 2D view) did not correspond to mid-point of the segment length. In the early foetal period, the primary ossification centre develops at the mid-point of the cartilage anlage and only later in the ensuing developmental stage become manifest the different longitudinal growth rate of the bone proximal and distal end. This specific character of long bone anlagen development was used to assess the longitudinal growth index of each hand segment: the narrower, transverse diameter of the diaphysis was traced on the digitalised X-ray image and the distance between this line and the proximal and distal ends was measured. When the definition of the narrower transverse diameter was uncertain, the proximal and distal boundaries of the narrow, central segment were traced: the mid-point of the central segment was assumed as the level of the narrower diameter (Fig. 1). The ratio between the distance of the mid-point and the proximal/distal ends (IGR)

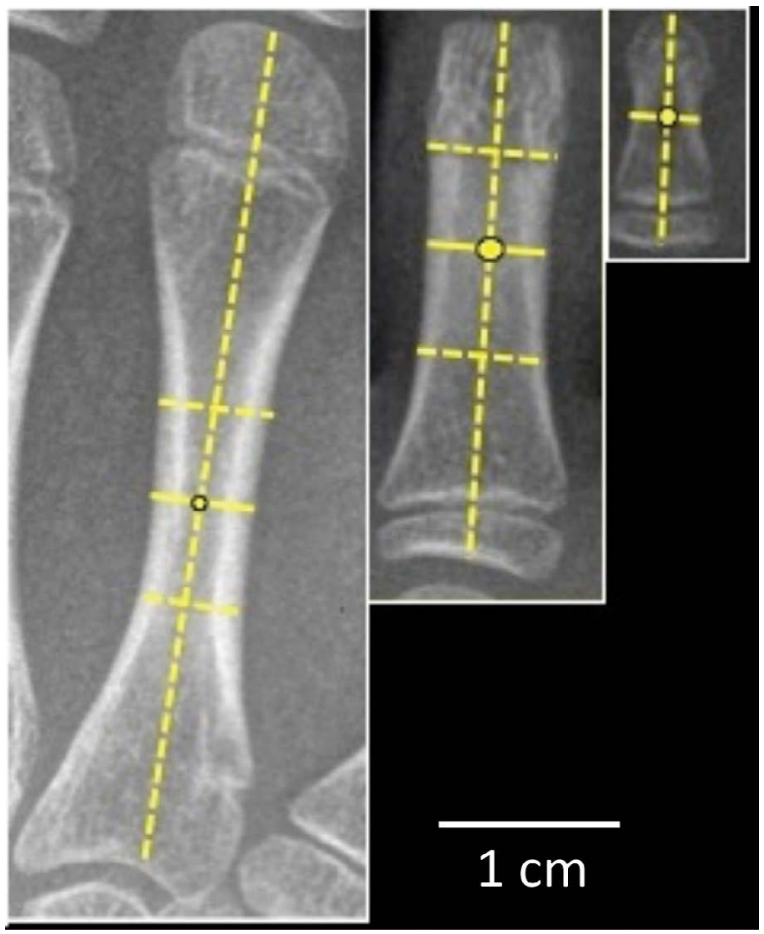

Figure 1. Method for the index of growth rate (IGR) measurement in long bones of post-natal hand X-rays. The narrower, transverse diameter of the diaphysis was traced in on the digitalised X-ray image and its distance from the distal and proximal end epiphyseal ends measured: $A B / A C=I G R$. When the definition of the narrower diameter was uncertain, the proximal and distal boundaries of the narrower central segment were traced: the mid-point of the latter was assumed as the narrower diameter (examples of measurement in metacarpal, mid and distal phalanx).

expressed the differential growth after cessation of the bidirectional growth pattern which characterises the growth phase of the post-natal age.

\section{Statistical analysis}

Repeated measurements of 20 normal hand X-ray images and of 95 - $\mathrm{FH} X$-rays were obtained independently by two investigators (A.G.S. and A.M.). Each data set was measured twice at interval of 1 month in two series of paired measurements. The difference of each paired measurements (intra-observer and inter-observer) was plotted against difference in individual segments and total ray length. By analysing the differences between the paired measurements, the variation in the differences for both the two series of measurements was wider in the inter-observed paired data set than in the corresponding intra-observer set; however, with a degree of agreement above $95 \%$ of confidence interval for both [11]. The finger segments relative length and the IGR was expressed as mean \pm standard error of mean (SEM). 

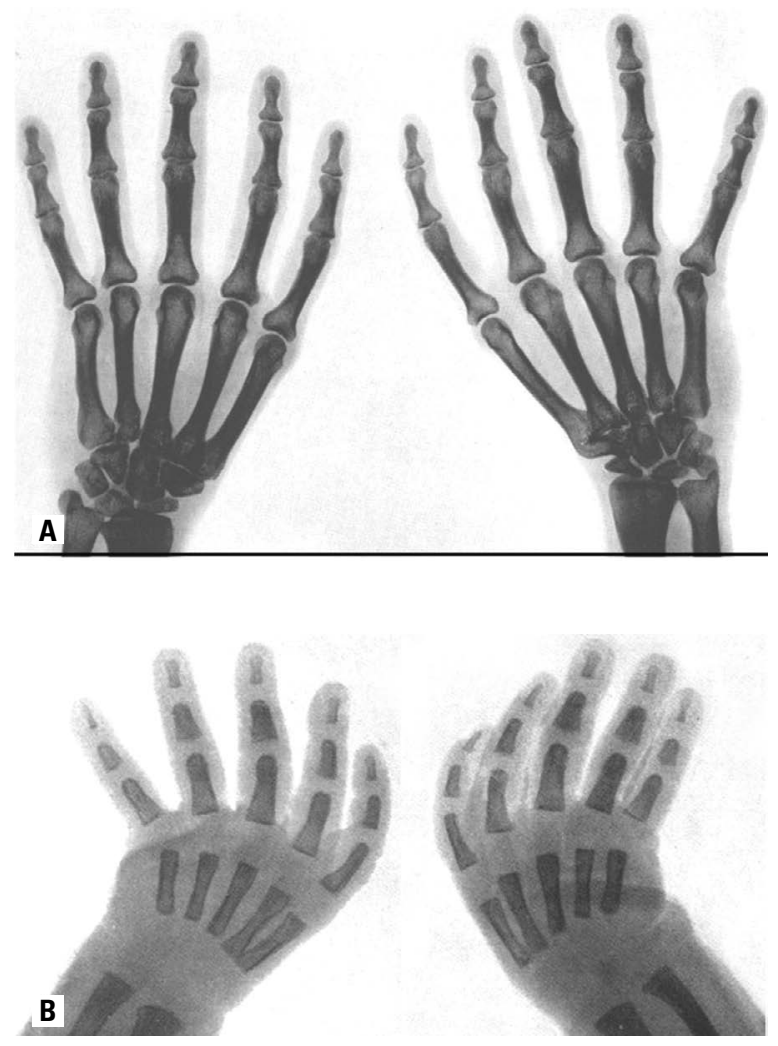

Figure 2. Five-fingered hand of the right and left hand of the mother (A) and of her new-born (B) reported by Heiss (1957) (reproduced from Zeitschrift fur Anatomieund Entwicklungsgeschichte with permission of Springer Nature; license n. 4334811065195).

Statistical analysis was performed with a statistical package (Graph Pad prism 5, Graph Pad Software, San Diego, CA, USA). Non parametric data were analysed by a Kruskall-Wallis test followed by Dunn's test or Mann-Withney test when appropriate.

\section{RESULTS}

The genetic transmission of 5-FH phenotype has been documented by the study of gene mutations in several cases with a large genealogical tree $[1,3,7$, $18,19]$; one of these hands $X$-ray image entered into the criteria of this study and could be analysed with morphometry. A further case reported by Heiss [6] documented bilateral 5-FH either in the mother (Fig. 2) and her new-born, confirming the genetic transmission. The relative length measurements of the 5-FH segments showed along each ray longitudinal axis same progression with $\mathrm{MC}>\mathrm{Php}>\mathrm{Phm}>\mathrm{Phd}$ (metacarpal; proximal phalanx; mid phalanx; distal phalanx). The comparison between the corresponding segment relative lengths in the transverse line (from ray 1 to ray 5) was variable, but with no-significant differences (Table 2, relative length). The IGR variance was wider among the distal phalanges, not significant among mid/proximal phalanges and metacarpals. The index of all metacarpals was $>1$ in contrast with that of all the phalanges which resulted $<1$ (Table 2, IGR). Comparing 5-FH and normal hand segments, the $2^{\text {nd }}-5^{\text {th }}$ ray showed no significant difference of relative length and IGR between corresponding segments (Table 3, relative length). The normal hand thumb ray (with the missing segment) was obviously much shorter than the 5- $\mathrm{FH} 1^{\text {st }}$ ray. Correction of the "missing element bias" of the normal hand $1^{\text {st }}$ ray segments with calculation of the relative length on the $3^{\text {rd }}$ of the same hand (instead of the $1^{\text {st }}$ ), homology resulted between the normal hand thumb metacarpal (anatomical) and the lateral proximal phalanges as well as between the thumb proximal phalanx (anatomical) and the lateral mid-phalanges (Table 3, relative length).

The IGR of normal hand $2^{\text {nd }}-5^{\text {th }}$ metacarpals was $>1$, that of the $1^{\text {st }}<1$, such as all the phalanges (Table 3, IGR). Both relative length and IGR of the thumb parameters were significantly different in the normal hand and in 5-FH series. In the latter $(n=9)$, three cases were reported as not-opposable thumb, in the remaining 6 hands this character was not reported. In the Heiss [6] case report the hands of the mother showed a synostosis of the right hand trapezius-metacarpal joint; however, also the flat and enlarged joint between the trapezius and the $1^{\text {st }}-2^{\text {nd }}$ left hand proximal metacarpals (Fig. 3) indicated a not-opposable thumb.

\section{DISCUSSION}

The concept of homology and its application in developmental biology is a cornerstone in the study of organismic diversity and evolution [16]. The issue of the limb bone segment development in the vertebrates offers an ideal field for the application of X-ray morphometry, in particular for what concerns the most distal limb sector, (the autopod) and the evolution of primates and the hominin family.

The measurement of the hand segment relative lengths on the total ray length was an unavoidable methodology to apply morphometry to published $\mathrm{X}$-ray images of $5-\mathrm{FH}$ because of the rare observation of this human phenotype and the consequent difficulty to collect the original documentation of old cases. Moreover, the morphometric comparison with the normal-hand population was complicated 
Table 2. Morphometric analysis of the hand segment relative lengths in the five-fingered hand (5-FH) series ( $n=9$ hands). The segment mean relative lengths along the ray longitudinal axis decreased from the metacarpal to the distal phalanx (MC): proximal phalanx (Php), mid phalanx (Phm), distal phalanx (Phd). Only statistical comparison of the mean relative lengths between corresponding segments in the transverse line was carried out and resulting not significant. Analysis of the hand segments' index of growth rate (IGR) in the 5-FH series ( $\mathrm{n}=9$ hands). All metacarpals $\left(1^{\text {th }}-5^{\text {th }}\right)$ have IGR $>1$, all phalanges IGR $<1$. This observation is relevant in the comparison with the normal human hand, whose thumb metacarpal (anatomical) has always IGR $<1$, like that of all the phalanges. It corresponds to the asymmetrical growth pattern of the human autopod segments, which is characterised by the development of a unique, epiphyseal ossification centre (see text). No other index inversions in the transversal line

\begin{tabular}{|c|c|c|c|c|c|c|c|c|}
\hline & MC & $\mathbf{P}$ & Php & $\mathbf{P}$ & $\mathrm{Phm}$ & $\mathbf{P}$ & Phd & $\mathbf{P}$ \\
\hline \multicolumn{9}{|c|}{ Relative length } \\
\hline $\mathrm{R} 1$ & $0.42 \pm 0.05$ & NS & $0.32 \pm 0.05$ & NS & $0.14 \pm 0.02$ & NS & $0.12 \pm 0.01$ & NS \\
\hline $\mathrm{R} 2$ & $0.49 \pm 0.04$ & & $0.27 \pm 0.02$ & & $0.17 \pm 0.01$ & & $0.07 \pm 0.02$ & \\
\hline R3 & $0.44 \pm 0.01$ & & $0.28 \pm 0.02$ & & $0.18 \pm 0.01$ & & $0.10 \pm 0.02$ & \\
\hline R4 & $0.42 \pm 0.02$ & & $0.30 \pm 0.02$ & & $0.18 \pm 0.02$ & & $0.11 \pm 0.03$ & \\
\hline R5 & $0.46 \pm 0.02$ & & $0.29 \pm 0.01$ & & $0.17 \pm 0.01$ & & $0.15 \pm 0.03$ & \\
\hline \multicolumn{9}{|c|}{ IGR } \\
\hline $\mathrm{R} 1$ & $0.92 \pm 0.06$ & & $0.84 \pm 0.05$ & & $0.63 \pm 0.03$ & & $0.33 \pm 0.04$ & \\
\hline $\mathrm{R} 2$ & $1.28 \pm 0.10$ & & $0.82 \pm 0.06$ & & $0.61 \pm 0.04$ & & $0.32 \pm 0.07$ & \\
\hline R3 & $1.31 \pm 0.08$ & & $0.83 \pm 0.05$ & & $0.62 \pm 0.06$ & & $0.32 \pm 0.07$ & \\
\hline R4 & $1.32 \pm 0.08$ & & $0.78 \pm 0.08$ & & $0.61 \pm 0.04$ & & $0.31 \pm 0.05$ & \\
\hline R5 & $1.35 \pm 0.08$ & & $0.82 \pm 0.05$ & & $0.62 \pm 0.05$ & & $0.32 \pm 0.05$ & \\
\hline
\end{tabular}

Data are show as mean \pm standard deviation; NS - not significant

Table 3. Relative length comparison in five-fingered hand (5-FH) (TPT; $n=9$ ) and normal hand series $(\mathrm{NH} ; n=20)$. The relative length of the $1^{\text {st }}$ ray segments normal hands was calculated on the total length of the $3^{\text {rd }}$ ray in the same hand. Comparison of index of growth rate (IGR) in normal hand and in 5-FH series. In the first series the thumb metacarpal is $<1$, the $2^{\text {nd }}-5^{\text {th }}>1$, in the second all metatarsals IGR is $>1$. All phalanges have IGR $<1$ with an index gradient corresponding to metacarpal $(\mathrm{MC}) \approx$ proximal phalanx $(\mathrm{Php}) \approx$ middle phalanx $(\mathrm{Phm}) \approx$ distal phalanx $(\mathrm{Phd})$

\begin{tabular}{|c|c|c|c|c|c|c|c|c|c|c|c|c|c|c|c|}
\hline & \multicolumn{3}{|c|}{ R1 } & \multicolumn{3}{|c|}{$\mathrm{R} 2$} & \multicolumn{3}{|c|}{ R3 } & \multicolumn{3}{|c|}{ R4 } & \multicolumn{3}{|c|}{ R5 } \\
\hline & TPT & NH & $\mathbf{P}$ & TPT & NH & $\mathbf{P}$ & TPT & NH & $\mathbf{P}$ & TPT & NH & $\mathbf{P}$ & TPT & NH & $\mathbf{P}$ \\
\hline \multicolumn{16}{|c|}{ Relative length } \\
\hline MC & $\begin{array}{c}0.42 \pm \\
0.05\end{array}$ & $\begin{array}{c}0.28 \pm \\
0.1\end{array}$ & NS & $\begin{array}{c}0.49 \pm \\
0.04\end{array}$ & $\begin{array}{c}0.48 \pm \\
0.05\end{array}$ & NS & $\begin{array}{c}0.44 \pm \\
0.01\end{array}$ & $\begin{array}{c}0.43 \pm \\
0.01\end{array}$ & NS & $\begin{array}{c}0.42 \pm \\
0.02\end{array}$ & $\begin{array}{c}0.4 \pm \\
0.01\end{array}$ & NS & $\begin{array}{c}0.46 \pm \\
0.02\end{array}$ & $\begin{array}{c}0.44 \pm \\
0.02\end{array}$ & NS \\
\hline Php & $\begin{array}{c}0.32 \pm \\
0.05\end{array}$ & $\begin{array}{l}0.19 \\
\pm 0\end{array}$ & $* * *$ & $\begin{array}{c}0.27 \pm \\
0.02\end{array}$ & $\begin{array}{c}0.25 \pm \\
0.08\end{array}$ & NS & $\begin{array}{c}0.28 \pm \\
0.02\end{array}$ & $\begin{array}{c}0.29 \pm \\
0.01\end{array}$ & NS & $\begin{array}{c}0.3 \pm \\
0.02\end{array}$ & $\begin{array}{c}0.29 \pm \\
0.01\end{array}$ & NS & $\begin{array}{c}0.29 \pm \\
0.01\end{array}$ & $\begin{array}{c}0.27 \pm \\
0.01\end{array}$ & NS \\
\hline Phm & $\begin{array}{c}0.14 \pm \\
0.02\end{array}$ & & & $\begin{array}{c}0.17 \pm \\
0.01\end{array}$ & $\begin{array}{c}0.16 \pm \\
0.02\end{array}$ & NS & $\begin{array}{c}0.18 \pm \\
0.01\end{array}$ & $\begin{array}{c}0.18 \pm \\
0.01\end{array}$ & NS & $\begin{array}{c}0.18 \pm \\
0.02\end{array}$ & $\begin{array}{c}0.18 \pm \\
0.01\end{array}$ & NS & $\begin{array}{c}0.17 \pm \\
0.01\end{array}$ & $\begin{array}{c}0.15 \pm \\
0.01\end{array}$ & NS \\
\hline Phd & $\begin{array}{c}0.12 \pm \\
0.01\end{array}$ & $\begin{array}{l}0.14 \\
\pm 0\end{array}$ & & $\begin{array}{c}0.07 \pm \\
0.02\end{array}$ & $\begin{array}{c}0.11 \pm \\
0.02\end{array}$ & $*$ & $\begin{array}{c}0.1 \pm \\
0.02\end{array}$ & $\begin{array}{c}0.11 \pm \\
0.01\end{array}$ & NS & $\begin{array}{c}0.11 \pm \\
0.03\end{array}$ & $\begin{array}{c}0.13 \pm \\
0.01\end{array}$ & NS & $\begin{array}{c}0.15 \pm \\
0.03\end{array}$ & $\begin{array}{c}0.14 \pm \\
0.01\end{array}$ & NS \\
\hline \multicolumn{16}{|l|}{ IGR } \\
\hline MC & $\begin{array}{c}0.92 \pm \\
0.06\end{array}$ & $\begin{array}{c}0.91 \pm \\
0.1\end{array}$ & NS & $\begin{array}{c}1.28 \pm \\
0.1\end{array}$ & $\begin{array}{c}1.18 \pm \\
0.06\end{array}$ & $* *$ & $\begin{array}{c}1.31 \pm \\
0.08\end{array}$ & $\begin{array}{c}1.11 \pm \\
0.07\end{array}$ & $* *$ & $\begin{array}{c}1.32 \pm \\
0.08\end{array}$ & $\begin{array}{c}1.15 \pm \\
0.12\end{array}$ & NS & $\begin{array}{c}1.35 \pm \\
0.08\end{array}$ & $\begin{array}{c}0.99 \pm \\
0.04\end{array}$ & $* * *$ \\
\hline Php & $\begin{array}{c}0.84 \pm \\
0.05\end{array}$ & $\begin{array}{c}0.87 \pm \\
0.1\end{array}$ & NS & $\begin{array}{c}0.82 \pm \\
0.06\end{array}$ & $\begin{array}{c}0.87 \pm \\
0.06\end{array}$ & NS & $\begin{array}{c}0.83 \pm \\
0.05\end{array}$ & $\begin{array}{c}0.85 \pm \\
0.11\end{array}$ & NS & $\begin{array}{c}0.78 \pm \\
0.08\end{array}$ & $\begin{array}{c}0.83 \pm \\
0.1\end{array}$ & NS & $\begin{array}{c}0.82 \pm \\
0.05\end{array}$ & $\begin{array}{c}0.87 \pm \\
0.07\end{array}$ & NS \\
\hline Phm & $\begin{array}{c}0.63 \pm \\
0.03\end{array}$ & & & $\begin{array}{c}0.61 \pm \\
0.04\end{array}$ & $\begin{array}{c}0.86 \pm \\
0.09\end{array}$ & $* * *$ & $\begin{array}{c}0.62 \pm \\
0.06\end{array}$ & $\begin{array}{c}0.83 \pm \\
0.11\end{array}$ & $* *$ & $\begin{array}{c}0.61 \pm \\
0.04\end{array}$ & $\begin{array}{c}0.92 \pm \\
0.15\end{array}$ & $* * *$ & $\begin{array}{c}0.62 \pm \\
0.05\end{array}$ & $\begin{array}{c}0.84 \pm \\
0.1\end{array}$ & $* * *$ \\
\hline Phd & $\begin{array}{c}0.33 \pm \\
0.04\end{array}$ & $\begin{array}{c}0.84 \pm \\
0.2\end{array}$ & $* * *$ & $\begin{array}{c}0.32 \pm \\
0.07\end{array}$ & $\begin{array}{c}0.35 \pm \\
0.1\end{array}$ & NS & $\begin{array}{c}0.32 \pm \\
0.07\end{array}$ & $\begin{array}{c}0.74 \pm \\
0.19\end{array}$ & $* * *$ & $\begin{array}{c}0.31 \pm \\
0.05\end{array}$ & $\begin{array}{c}0.4 \pm \\
0.06\end{array}$ & $* *$ & $\begin{array}{c}0.32 \pm \\
0.05\end{array}$ & $\begin{array}{c}0.32 \pm \\
0.13\end{array}$ & NS \\
\hline
\end{tabular}

Data are show as mean \pm standard deviation; NS - not significant; ${ }^{*} p<0.05 ;{ }^{* *} p<0.01 ;{ }^{* * *} p<0.001$ 


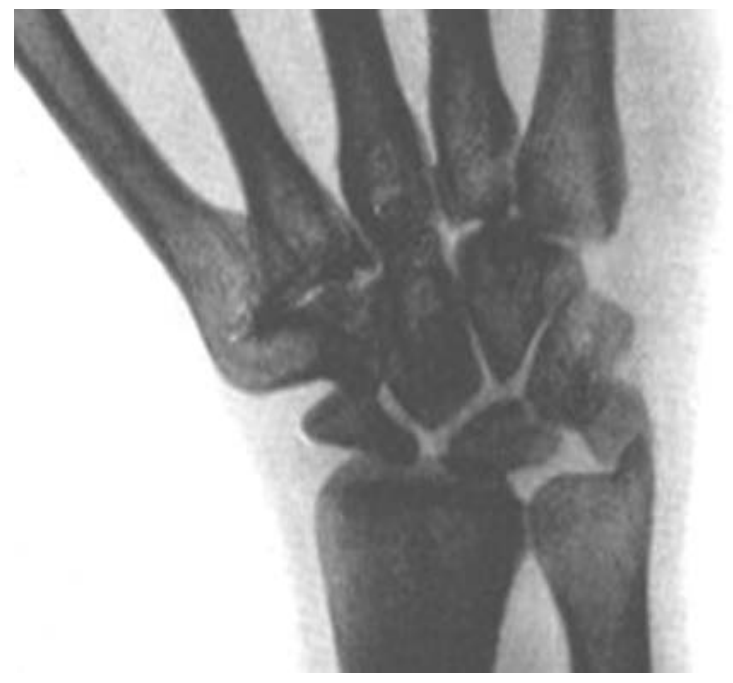

Figure 3. Detail of Figure 2, elaborated with the "relief" function to enhance the relationship between trapezius $-1^{\text {st }}$ and $2^{\text {nd }}$ proximal metacarpals: synostosis trapezius- $1^{\text {st }}$ metacarpal in the right hand and a flat/enlarged trapezius joint surface with the $1^{\text {st }}$ and $2^{\text {nd }}$ metacarpals in the left hand. Both correspond to a not-opposable thumb.

by the "thumb missing segment bias" of the latter population which reduced the total length of the $1^{\text {st }}$ ray (thus increasing the relative lengths of the ray segments). Therefore, a correction factor was introduced in the normal-hands population calculating the relative length of the thumb segments on the $3^{\text {rd }}$ ray of the same hand total length. The choice of the $3^{\text {rd }}$ ray was based on the observation that in the 5-FH series the $3^{\text {rd }}$ ray total length gave the best approximation to that of the thumb without a missing element.

Shape and topology were the currently used criteria to recognise the individuality of the hand segments as the metacarpals and respectively the proximal, mid and distal phalanges. The morphometric analysis of 5-FH confirmed with the parameters of relative length and IGR the homology of the segments at the same level in the transverse line of metacarpals and phalanges. In the human hand evolution, the loss of one segment of the $1^{\text {st }}$ ray and the acquired ability of the thumb opposition has raised a long lasting discussion on the thumb segments homology with that of the lateral four metacarpals and phalanges $[4,15]$.

The unanswered question in this discussion was if the proximal segment of the thumb should be considered as a true metapodial or a phalanx and if the missing segment was the metacarpal or alternatively the proximal or the mid phalanx.

The 5-FH phenotype has been considered the result of a repeated, occasional gene mutation in the chromosomal region $7 q 36[2,7]$ and it was suggested that it could be an ancestral phenotype in the evolution of anthropoids and hominids [8, 9, 11, 17]. However, to the best of our knowledge no observations of this autopod pattern have been reported in palaeontology or in the phylogenesis of vertebrates. These considerations were used to support the theory that the proximal thumb segment in the modern humans was a modified metapodial [4], but it does not give an explanation of the thumb missing segment (accordingly to this theory the proximal or the mid phalanx).

The comparative relative length analysis between the $1^{\text {st }}$ ray segments of normal-hand and that of the 5-FH series suggested homology between metacarpal $\neq$ proximal-phalanx and proximal-phalanx $\neq$ mid-phalanx.

In this context, the IGR (which can be easily determined in the human hands post-natal X-rays) offered further insights in this discussion. The development of the human autopod was characterised by two different growth patterns. The first with a symmetric proximal and distal length growth of the cartilage anlage and the formation of the primary ossification centre in the embryonic and early foetal phase. The second with the appearance of the epiphyseal ossification centre in the late foetal and post-natal age $[12,13]$. The narrower mid-transverse section of the primary ossification centre corresponded to the mid-point of the cartilage anlage characterised by the symmetric length growth of both ends during the whole foetal phase and until the epiphyseal centres development. Therefore, the post-natal X-rays of both 5-FH and normal hands after the formation of the single epiphyseal centre (and of the related growth plate cartilage) can be used to measure the distal and proximal segmental growth. It is worth to underscore that this parameter is independent from the relative length measurement.

Since IGR $>1$ in 5-FH was the typical pattern of metacarpals, opposed to IGR $<1$ of all the phalanges, the observation of the ratio $<1$ in the normal-hand series $1^{\text {st }}$ ray proximal segment (a metacarpal accordingly to the current anatomical nomenclature), further reinforced the homology suggested by the thumb relative length measurement, that is a correspondence metacarpal $\approx$ proximal phalanx and proximal phalanx $\approx$ mid phalanx.

This study presents some limitations, as frequently observed in comparative meta-analysis. First of 
all, and since the topic refers to a rather infrequent condition, some papers included in this analysis are not very recent and thus include older elaboration techniques for X-ray images which may influence the included data. Secondly, we opted for the measurement of the $3^{\text {rd }}$ ray together with a correction factor in order to achieve the most accurate approximation measurement.

\section{CONCLUSIONS}

The comparative analysis of relative lengths and IGRs in the two groups suggested homology of the (anatomical) thumb metacarpal with the $2^{\text {nd }} 5^{\text {th }}$ ray proximal phalanges in the same hand and that of the (anatomical) thumb proximal phalanx with the $2^{\text {nd }}-5^{\text {th }}$ ray mid-phalanges. These data suggest that in the human hand the missing segment of the thumb is the metacarpal.

\section{REFERENCES}

1. Bland JM, Altman DG, Elsner JJ, et al. Statistical methods for assessing agreement between two methods of clinical measurement. Lancet. 1986; 1(8476): 307-310, indexed in Pubmed: 2868172.

2. Dobbs MB, Dietz FR, Gurnett CA, et al. Localization of dominantly inherited isolated triphalangeal thumb to chromosomal region 7q36. J Orthop Res. 2000; 18(3): 340-344, doi: 10.1002/jor.1100180303, indexed in Pubmed: 10937618.

3. Girisha KM, Bidchol AM, Kamath PS, et al. A novel mutation (g.106737G $>$ T) in zone of polarizing activity regulatory sequence (ZRS) causes variable limb phenotypes in Werner mesomelia. Am J Med Genet A. 2014; 164A(4): 898-906, doi: 10.1002/ajmg.a.36367, indexed in Pubmed: 24478176.

4. Guillem P, Demondion X, Drizenko A, et al. La bio phalange du pouce. Revue générale de la literature. Morphologie. 1999; 83: 27-31.

5. Haines RW. The pseudo epiphysis of the first metacarpal of man. J Anat. 1974; 117: 145-158.

6. Heiss $\mathrm{H}$. [Bilateral congenital thumbless five-finger hand in mother and child]. Z Anat Entwicklungsgesch. 1957; 120(3): 226-231, indexed in Pubmed: 13531207.

7. Heutink $P$, Zguricas J, van Oosterhout $L$, et al. The gene for triphalangeal thumb maps to the subtelomeric region of chromosome 7q. Nat Genet. 1994; 6(3): 287-292, doi: 10.1038/ng0394-287, indexed in Pubmed: 8012392.

8. Marzke MW, Marzke RF. Evolution of the human hand: approaches to acquiring, analysing and interpreting the anatomical evidence. J Anat. 2000; 197 (Pt 1): 121-140, doi: 10.1046/j.1469-7580.2000.19710121.x, indexed in Pubmed: 10999274.

9. Marzke MW. Precision grips, hand morphology, and tools. Am J Phys Anthropol. 1997; 102(1): 91-110, doi: 10.1002/(SICI)1096-8644(199701)102:1<91::AIDAJPA8>3.0.CO;2-G, indexed in Pubmed: 9034041.

10. Ogden JA, Ganey TM, Light TR, et al. Ossification and pseudoepiphysis formation in the "nonepiphyseal" end of bones of the hands and feet. Skeletal Radiol. 1994; 23(1): 3-13, doi: 10.1007/BF00203694, indexed in Pubmed: 8160033.

11. Patel B, Maiolino S. Morphological diversity in the digital rays of primate hands. In Kivell TL, Lemelin, P, Richmond, BG, et al (eds). The evolution of the primate hand. Springer Science New York. The Evolution of the Primate Hand. 2016: 55-100, doi: 10.1007/978-1-4939-3646-5 4.

12. Pazzaglia UE, Congiu T, Sibilia V, et al. Growth and shaping of metacarpal and carpal cartilage anlagen: application of morphometry to the development of short and long bone. A study of human hand anlagen in the fetal period. J Morphol. 2017; 278(7): 884-895, doi: 10.1002/jmor.20681, indexed in Pubmed: 28386944.

13. Pazzaglia UE, Congiu T, Sibilia V, et al. Relationship between the chondrocyte maturation cycle and the endochondral ossification in the diaphyseal and epiphyseal ossification centers. J Morphol. 2016; 277(9): 1187-1198, doi: 10.1002/jmor.20568, indexed in Pubmed: 27312928.

14. Qazi Q, Kassner EG. Triphalangeal thumb. J Med Genet. 1988; 25(8): 505-520, doi: 10.1136/jmg.25.8.505, indexed in Pubmed: 3050097.

15. Reno PL, Horton WE, Lovejoy CO. Metapodial or phalanx? An evolutionary and developmental perspective on the homology of the first ray's proximal segment. J Exp Zool B Mol Dev Evol. 2013; 320(5): 276-285, doi: 10.1002/ jez.b.22506, indexed in Pubmed: 23640850.

16. Rieppel O. Homology, topology, and typology: the history of modern debates. In Hall BK (ed). Homology: the hierarchical basis of comparative biology. Academic Press Inc. Homology. 1994: 63-100, doi: 10.1016/b978-0-12318920-2.50008-1.

17. Tocheri MW, Orr CM, Jacofsky MC, et al. The evolutionary history of the hominin hand since the last common ancestor of Pan and Homo. J Anat. 2008; 212(4): 544-562, doi: 10.1111/j.1469-7580.2008.00865.x, indexed in Pubmed: 18380869

18. Warm A, Di Pietro C, D'Agrosa F, et al. Non-opposable triphalangeal thumb in an Italian family. J Med Genet. 1988; 25(5): 337-339, doi: 10.1136/jmg.25.5.337, indexed in Pubmed: 3385742.

19. Wieczorek D, Pawlik B, Li Y, et al. A specific mutation in the distant sonic hedgehog (SHH) cis-regulator (ZRS) causes Werner mesomelic syndrome (WMS) while complete ZRS duplications underlie Haas type polysyndactyly and preaxial polydactyly (PPD) with or without triphalangeal thumb. Hum Mutat. 2010; 31(1): 81-89, doi: 10.1002/ humu.21142, indexed in Pubmed: 19847792.

20. Zguricas J, Dijkstra PF, Gelsema ES, et al. Metacarpophalangeal pattern (MCPP) profile analysis in a family with triphalangeal thumb. J Med Genet. 1997; 34(1): 55-62, doi: 10.1136/jmg.34.1.55, indexed in Pubmed: 9032651.

21. Zuidam JM, Dees EEC, Lequin MH, et al. The effect of the epiphyseal growth plate on the length of the first metacarpal in triphalangeal thumb. J Hand Surg Am. 2006; 31(7): 1183-1188, doi: 10.1016/j.jhsa.2006.03.025, indexed in Pubmed: 16945724.

22. Zuidam JM, Dees EEC, Selles RW, et al. Implications for treatment of variations in length of the first metacarpal in different types of triphalangeal thumbs. J Hand Surg Eur Vol. 2010; 35(1): 65-69, doi: 10.1177/1753193408095881, indexed in Pubmed: 20100712. 